\title{
PARÂMETROS FISIOLÓGICOS E PRODUTIVIDADE DE ESPIGAS VERDES DE MILHO SOB DIFERENTES LÂMINAS DE IRRIGAÇÃO ${ }^{1}$
}

\author{
FÁBIO NUNES DO NASCIMENTO², EDSON ALVES BASTOS 3 , \\ MILTON JOSÉ CARDOSO ${ }^{3}$, ADERSON SOARES DE ANDRADE JÚNIOR ${ }^{3}$ \\ e VALDENIR QUEIROZ RIBEIRO 3
}

\author{
${ }^{1}$ Parte da dissertação de mestrado do primeiro autor apresentada \\ ao programa de pós-graduação em Agronomia - Universidade Federal do Piauí. \\ ${ }^{2}$ IFPI, Valença, PI, Brasil, fabio.nunes@ifpi.edu.br \\ ${ }^{3}$ Embrapa Meio-Norte, Teresina,PI, edson.bastos@embrapa.br, \\ milton.cardoso@embrapa.br,aderson.andrade@embrapa.br,valdenir.queiroz@embrapa.br
}

Revista Brasileira de Milho e Sorgo, v.14, n.2, p. 167-181, 2015

\begin{abstract}
RESUMO - O objetivo do trabalho foi avaliar a influência de diferentes lâminas de irrigação sobre alguns parâmetros fisiológicos do milho verde, como índice de área foliar (IAF) e teor de clorofila total, relacionando-os com a produtividade de espigas verdes e com a eficiência do uso da água. O experimento foi conduzido de setembro a novembro de 2009, em Teresina- PI, na Embrapa Meio-Norte, em um Argissolo Vermelho Amarelo eutrófico. A cultivar utilizada foi o híbrido duplo AG1051. O delineamento experimental foi o de blocos ao acaso com quatro repetições, como tratamentos cinco lâminas de irrigação baseadas em frações da evapotranspiração de referência $(25 \%, 50 \%, 75 \%, 100 \%$ e $125 \%$ da evapotranspiração de referência - ETo). Os melhores resultados foram 13.453,13 $\mathrm{kg} \mathrm{ha}^{-1} \mathrm{e} 8.465,62 \mathrm{~kg} \mathrm{ha}^{-1} \mathrm{de}$ espigas verdes empalhadas e despalhadas, respectivamente, os quais foram obtidos com a maior lâmina aplicada. $\mathrm{O}$ déficit hídrico imposto no estádio V6 (sexta folha) reduziu linearmente o índice de área foliar e o teor de clorofila total. Houve uma correlação positiva significativa $(\mathrm{p}<0,05)$ da produtividade de espigas verdes despalhadas com o IAF e o teor de clorofila total. A mais alta eficiência do uso da água $\left(2,48 \mathrm{~kg} \mathrm{~m}^{-3}\right)$ foi obtida com aplicação da maior lâmina $(340,57 \mathrm{~mm})$. Palavras-chave: Zea mays L., clorofila, índice de área foliar, correlação.
\end{abstract}

\section{PHYSIOLOGICAL PARAMETERS AND PRODUCTIVITY OF GREEN CORN UNDER DIFFERENT IRRIGATION LEVELS}

\begin{abstract}
The aim of this study was to evaluate the influence of different irrigation levels on some physiological parameters of green corn, such as leaf area index and total chlorophyll content, correlated to green ear yield and water use efficiency. The experiment was conducted from September to November 2009 in Teresina, Piauí State, Brazil, at Embrapa Meio-Norte, in an eutrophic Alfissol, using the double hybrid AG1051. The experimental design was a randomized block design with four replications and five irrigation treatments based on fractions of the evapotranspiration reference $(25 \%, 50 \%, 75 \%, 100 \%$ and $125 \%$ of the reference evapotranspiration - ETo). The best results were $13,453.13 \mathrm{~kg} \mathrm{ha}^{-1}$ and $8,465.62 \mathrm{~kg} \mathrm{ha}^{-1}$ of ears with husk and without husk, respectively, obtained with the largest water level. The water deficit imposed at the V6 stage (sixth full leaf) linearly reduced leaf area index and total chlorophyll content. A significant positive correlation $(\mathrm{p}<0.05)$ was observed between productivity of unhusked green ears and leaf area index and total chlorophyll content. The highest efficiency of water use $2.48 \mathrm{~kg} \mathrm{~m}^{-3}$ was obtained with application of higher water level $(340.57 \mathrm{~mm})$.
\end{abstract}

Key words: Zea mays $L$., chlorophyll, leaf area index, correlation. 
O milho verde, em sua maioria, é produzido em pequenas propriedades, em que o uso de sistemas de irrigação ainda é limitado. As culturas, durante o seu ciclo de desenvolvimento, consomem grande volume de água, sendo que por volta de $98 \%$ deste volume passam através da planta, por meio do processo de transpiração (Gordon et al., 1995). Este fluxo de água é necessário para o desenvolvimento vegetal.

A quantidade de água que o milho verde utiliza durante o ciclo é chamada demanda sazonal, podendo variar com as condições climáticas da região onde é cultivado. Há um período durante o ciclo da cultura em que mais água é consumida diariamente. No caso do milho, esse período coincide com o florescimento e o enchimento de grãos e um estresse hídrico nessa fase pode causar diversos prejuízos para o agricultor, notadamente reduzindo a produtividade da cultura.

O déficit hídrico pode afetar os vegetais sob diferentes aspectos, apresentando desempenho ecofisiológico diferente quando sob disponibilidade hídrica limitada (Santos et al., 2014). Outros parâmetros também podem ser afetados pelo déficit hídrico, como índice de área foliar (IAF), teor de clorofila e eficiência do uso da água.

Para se caracterizar a área foliar que cobre um terreno, comumente se utiliza o índice de área foliar, citado por Watson (1947), como sendo a área de folhas por área. Muitos trabalhos revelam pequeno IAF no início da cultura justificado pelo seu lento crescimento naquela fase, seguido de rápido aumento que perdura até chegar ao seu valor máximo.

Vários trabalhos com milho registraram redução no IAF em decorrência da deficiência hídrica. Parizi (2007) obteve 6,08 aos 74 dias após a emergência e 5,3 aos 90 dias após a emergência.
Maddonni \& Otegui (1996) observaram decréscimo após os 100 dias, com valores variando entre 1,5 e 3,0 .

Segundo Torres Netto et al. (2005), a determinação indireta do teor de clorofila em folhas pode ser usada como ferramenta para diagnosticar a integridade do aparelho fotossintético, quando as plantas estão sujeitas às adversidades ambientais.

Para a eficiência do uso da água, Albuquerque $\&$ Resende (2009) consideram a cultura do milho conhecida por sua grande demanda, mas também é uma das mais eficientes no uso da água, isto é, produz uma grande quantidade de matéria seca por unidade de água absorvida.

Nesse contexto, o presente trabalho teve como objetivos avaliar o índice de área foliar, o teor de clorofila total, a eficiência do uso da água e a produtividade de espigas verde de milho sob diferentes lâminas de irrigação no município de Teresina-PI.

\section{Material e Métodos}

O experimento foi conduzido no período de setembro a novembro de 2009, em Teresina-PI, cujas coordenadas são- $5^{\circ} 05^{\prime} \mathrm{S}$ de latitude, $42^{\circ} 48^{\prime} \mathrm{W}$ de longitude e 74,4 $\mathrm{m}$ de altitude, localizado no campo Experimental da Embrapa Meio-Norte. O clima do município, de acordo com a classificação climática

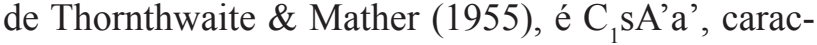
terizado como subúmido seco, megatérmico, com excedente hídrico moderado no verão.

Durante o trimestre setembro-outubro-novembro, ocorre uma concentração de 32\% da evapotranspiração potencial anual, sendo que as médias anuais de umidade relativa do ar e de índice pluviométrico são de $72,6 \%$ e $1.336,5 \mathrm{~mm}$, respectivamente, con- 
centrando a maioria das chuvas de janeiro a abril (Bastos \& Andrade Júnior, 2008).

O delineamento estatístico usado foi o de blocos ao acaso, com quatro repetições. Os tratamentos, dispostos em faixa, constaram de cinco lâminas de irrigação, considerando as seguintes variações da evapotranspiração de referência (ETo): $25 \%$ da ETo; $50 \%$ da ETo; $75 \%$ da ETo; $100 \%$ da ETo; e 125\% da ETo.

As parcelas experimentais constaram de seis fileiras de $7 \mathrm{~m}$ de comprimento e, como área útil, foram consideradas as quatro fileiras centrais representadas por uma área de $3,20 \mathrm{~m} \mathrm{x} \mathrm{5,0} \mathrm{m,} \mathrm{totalizando} 16 \mathrm{~m}^{2}$.
O solo da área é um Argissolo Vermelho Amarelo eutrófico (Santos et al., 2006), cujas características químicas e físico-hídricas encontram-se nas Tabelas 1 e 2 , respectivamente.

A curva de retenção de água realizada na profundidade (P01) de 0,00 $\mathrm{m}$ a 0,20 $\mathrm{m}$ apresentou capacidade de campo igual a $0,22 \mathrm{~cm}^{3} \mathrm{~cm}^{-3}$ e ponto de murcha permanente igual a $0,09 \mathrm{~cm}^{3} \mathrm{~cm}^{-3}$. Na profundidade (P02) de 0,20 m a 0,40 m, a capacidade de campo teve o mesmo comportamento dos primeiros $20 \mathrm{~cm}$ e o ponto de murcha foi de $0,11 \mathrm{~cm}^{3} \mathrm{~cm}^{-3}$ (Figura 1).

TABELA 1. Características químicas do solo da área experimental. Embrapa Meio-Norte, Teresina-PI.

\begin{tabular}{ccccccccccc}
\hline Prof. & $\mathrm{MO}$ & $\mathrm{pH}$ & $\mathrm{P}$ & $\mathrm{K}^{+}$ & $\mathrm{Ca}^{+}$ & $\mathrm{Mg}^{+}$ & $\mathrm{Na}+$ & $\mathrm{H}^{+}+\mathrm{Al}^{+}$ & $\mathrm{CTC}$ & $\mathrm{V}$ \\
$(\mathrm{m})$ & $\mathrm{g} \mathrm{kg}^{-1}$ & (água) & $\left(\mathrm{mg} \mathrm{dm}^{-3}\right)$ & $-----------------\left(\mathrm{mmol}_{\mathrm{c}} \mathrm{dm}^{-3}\right)$ & & & & & \\
\hline $0,00-0,20$ & 4,20 & 5,78 & 33,80 & 1,7 & 1,7 & 7,6 & 0,1 & 21,5 & 45,6 & 52,91 \\
$0,20-0,40$ & 4,15 & 5,37 & 14,10 & 1,3 & 1,3 & 5,8 & 0,1 & 33,8 & 58,9 & 42,60 \\
\hline
\end{tabular}

Fonte: Laboratório de Solos da Embrapa Meio-Norte.

TABELA 2. Características físico-hídricas do solo da área experimental. Embrapa Meio-Norte, Teresina-PI.

$$
\text { Características }
$$

Densidade do solo $\left(\mathrm{kg} \mathrm{m}^{-3}\right)$

Areia grossa $\left(\mathrm{g} \mathrm{kg}^{-1}\right)$

Areia fina $\left(\mathrm{g} \mathrm{kg}^{-1}\right)$

Silte $\left(\mathrm{g} \mathrm{kg}^{-1}\right)$

Argila $\left(\mathrm{g} \mathrm{kg}^{-1}\right)$

$\mathrm{CC}\left(\mathrm{cm}^{3} \mathrm{~cm}^{-3}\right)$

$\operatorname{PM}\left(\mathrm{cm}^{3} \mathrm{~cm}^{-3}\right)$
Camadas do solo $(\mathrm{m})$

$0,00-0,20 \quad 0,20-0,40$

Fonte: Laboratório de Solos da Embrapa Meio-Norte. 


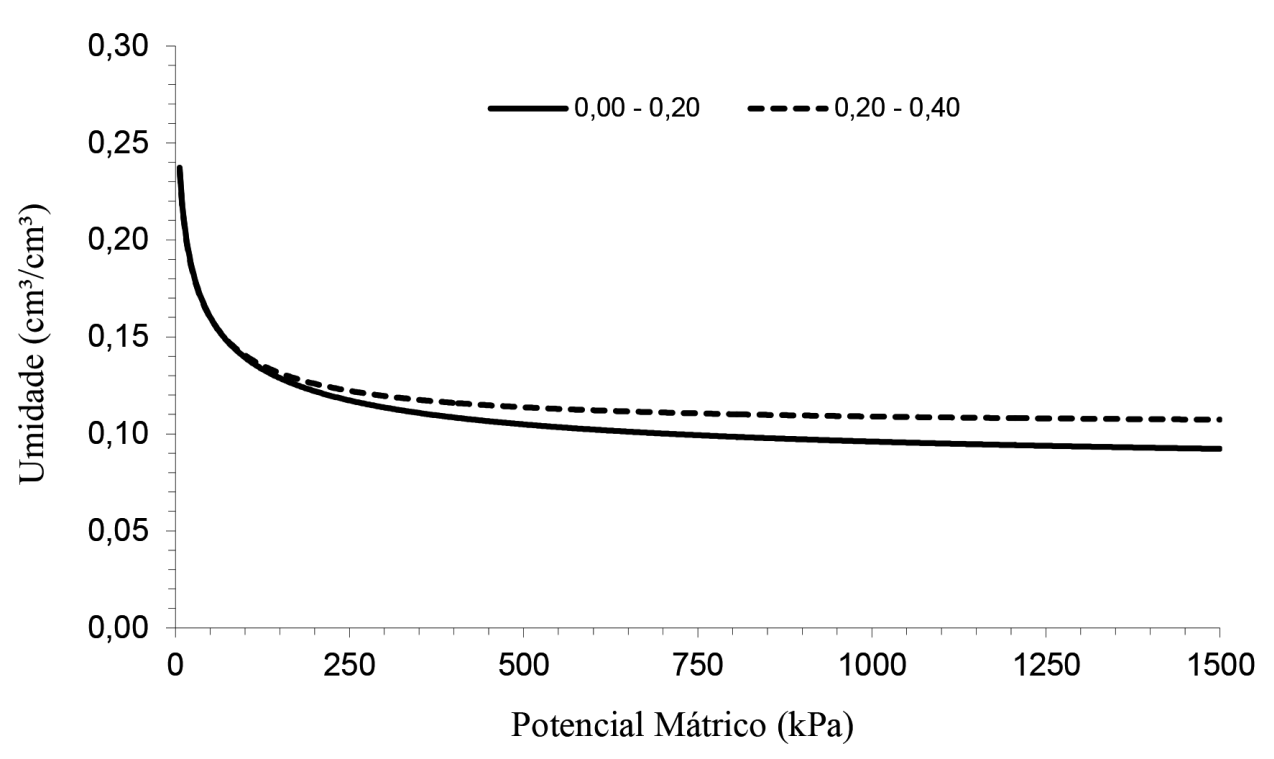

FIGURA 1. Curva de retenção de água no solo da área experimental. Teresina-PI, 2009.

O preparo do solo consistiu de uma aração e duas gradagens leves. A semeadura foi manual, com auxílio de uma matraca, em um espaçamento de 0,80 $\mathrm{m} \times 0,25 \mathrm{~m}$. A adubação de semeadura foi $40 \mathrm{~kg} \mathrm{ha}^{-1}$ de $\mathrm{N}, 80 \mathrm{~kg} \mathrm{ha}^{-1}$ de $\mathrm{P}_{2} \mathrm{O}_{5}$ e $35 \mathrm{~kg} \mathrm{ha}^{-1}$ de $\mathrm{K}_{2} \mathrm{O}$. Foram feitas duas adubações de cobertura, a primeira por ocasião da sexta folha completamente desenvolvida, com $40 \mathrm{~kg}$ de $\mathrm{N} \mathrm{ha}^{-1}$ mais $35 \mathrm{~kg}$ de $\mathrm{K}_{2} \mathrm{O}$ ha $^{-1}$, e a segunda com $40 \mathrm{~kg}$ de $\mathrm{N} \mathrm{ha}^{-1}$, quando as plantas estavam com oito folhas completamente desenvolvidas. $\mathrm{Na}$ semeadura, a fonte de $\mathrm{N}$ foi a ureia, de $\mathrm{P}_{2} \mathrm{O}_{5} \mathrm{O}$ superfosfato simples e a de $\mathrm{K}_{2} \mathrm{O}$ o cloreto de potássio. Já em cobertura, foram o sulfato de amônio como fonte de $\mathrm{N}$ e o cloreto de potássio como fonte de $\mathrm{K}_{2} \mathrm{O}$.

A cultivar usada neste estudo foi o híbrido duplo de milho AG1051, de ciclo semiprecoce, grão amarelo e textura dentada, alta resistência ao acamamento. O desbaste foi realizado 15 dias após a semeadura (DAS), deixando uma planta por cova para um estande final de 50.000 plantas por hectare.
O controle de plantas daninhas foi feito com capinas aos 12 e 22 DAS, com enxada e tração animal, respectivamente. Foram utilizados dois inseticidas, com os seguintes princípios ativos: Lufenuron ( $\left.1 \mathrm{ml} \mathrm{L}^{-1}\right)$, que age sem efeito de choque sobre as pragas, manifestando a sua plena eficiência dos três aos cinco dias após a aplicação; e Lambdacyhalothrin $\left(1 \mathrm{ml} \mathrm{L}^{-1}\right)$, que é um inseticida que age por ingestão e contato, com número de aplicações variando de acordo com a infestação. As aplicações ocorreram aos 16 DAS e 38 DAS, objetivando o controle da população da lagarta-do-cartucho (Spodoptera frugiperda, Smith).

O sistema de irrigação utilizado foi por aspersão convencional fixo, com aspersores de impacto, com bocais de 4,4 mm x 3,2 mm, vazão de 1,59 $\mathrm{m}^{3}$ $\mathrm{h}^{-1}$ funcionando a uma pressão de serviço de $3,0 \times 10^{6}$ $\mathrm{Pa}$, espaçados de $12 \mathrm{~m}$ x $12 \mathrm{~m}$. Os valores médios das lâminas aplicadas por faixa foram determinados utilizando-se coletores, instalados nas parcelas, medindo- 
se o volume de água coletado com proveta graduada em mm após as irrigações.

O manejo de irrigação baseou-se nos valores da evapotranspiração de referência (ETo), estimados pelo modelo de Penman-Monteith (Allen et al., 1998). As lâminas foram determinadas em função dos tratamentos e os dados climáticos foram obtidos em uma estação meteorológica automática, próxima à área experimental.

O monitoramento do teor de água no solo foi executado por meio de uma sonda de capacitância (FDR) modelo Diviner $2000 \AA$, que é um equipamento portátil que utiliza o princípio da capacitância elétrica e monitora o teor de água no solo a cada $0,10 \mathrm{~m}$ a até 1,0 $\mathrm{m}$ de profundidade. As leituras de frequência relativa (FR) foram diárias e também antes e 24 horas após a aplicação das lâminas de irrigação. Para tanto, foram instalados 15 tubos de acesso em PVC, com 1,5 m de comprimento, na direção perpendicular à aplicação das lâminas de irrigação, sendo três tubos em cada faixa.

A colheita foi realizada manualmente aos 68 DAS. Os dados do índice de área foliar (IAF) foram obtidos através da seleção de uma planta por parcela, nas repetições em cada uma das cinco faixas. As medidas das folhas tiveram início aos 30 DAS e depois a cada 14 dias e foram obtidas de todas as folhas das plantas selecionadas com auxilio de uma trena. A área foliar foi determinada multiplicando-se o comprimento e a largura máxima das folhas por um fator 0,75 (Petry et al., 2007).

O teor de clorofila total foi determinado utilizando-se um clorofiLOG CFL 1030. A primeira leitura foi aos 38 DAS e as demais a cada sete dias, até a colheita. Os dados foram mensurados nas folhas verdes, completamente expandidas, de dez plantas de cada parcela e o valor da parcela foi obtido calculando-se a média das leituras.
A eficiência do uso de água foi calculada pela relação entre a produtividade de espigas despalhadas $\left(\mathrm{kg} \mathrm{ha}^{-1}\right)$ (PEDHA) e o volume total de água aplicada $\left(\mathrm{em} \mathrm{m}^{-3}\right)$. As produtividades das espigas empalhadas por hectare (PEEHA) e despalhadas por hectare (PEDHA) foram obtidas pela colheita feita na área útil $\left(16 \mathrm{~m}^{2}\right)$ de todas as parcelas, sendo pesadas com o auxílio de uma balança.

Os dados obtidos foram submetidos à análise de variância, considerando-se o efeito de tratamento como fixo e os demais como aleatórios. A fim de verificar a influência das lâminas de irrigação sobre a produtividade de espiga verde de milho, estimou-se uma função de resposta por meio de uma regressão polinomial, usando-se o programa computacional estatístico SAS (Sas Institute, 2002).

\section{Resultados e Discussão}

Durante a condução do experimento, a precipitação foi de $16,2 \mathrm{~mm}$, distribuída nos três últimos decêndios, com valores de 9,3 mm, 5,9 mm e 1,0 mm, respectivamente, conforme Figura 2.

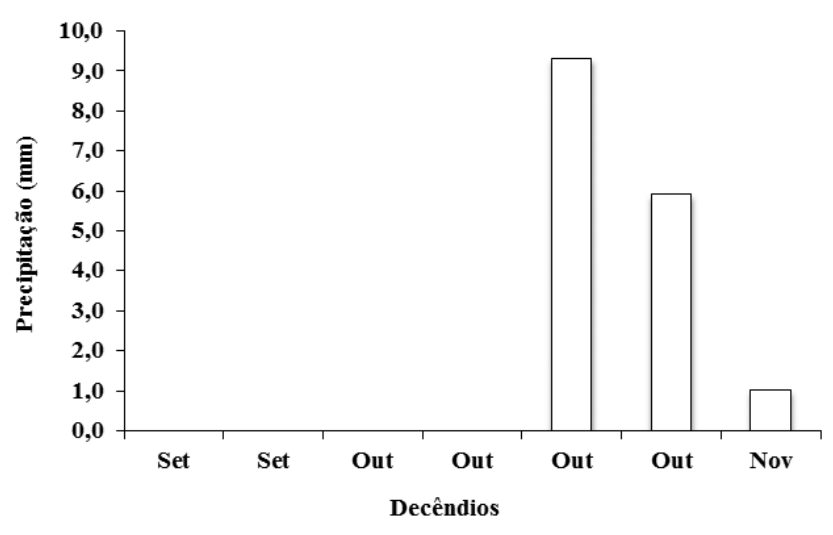

FIGURA 2. Valores acumulados de precipitação pluviométrica para os decêndios dos meses de setembro, outubro e novembro de 2009, Teresina-PI, 2009. 
Dados observados da umidade relativa do ar demonstraram que os valores mantiveram-se na faixa de $61,92 \%$ a $67,65 \%$ durante os decêndios da condução do experimento, as temperaturas mínimas apresentaram uma variação de $22{ }^{\circ} \mathrm{C}$ a $23{ }^{\circ} \mathrm{C}$, as médias de $28^{\circ} \mathrm{C}$ a $29^{\circ} \mathrm{C}$ e as máximas entre $35^{\circ} \mathrm{C}$ e $37^{\circ} \mathrm{C}$ no decorrer dos decêndios.

A aplicação das frações de 25\%, 50\%, 75\%, $100 \%$ e $125 \%$ da ETo resultou nas seguintes lâminas totais de irrigação: $165,51 \mathrm{~mm}$ (L5); 208,85 mm (L4); 255,32 mm (L3); 304,39 mm (L2); e 340,57 $\mathrm{mm}$ (L1), respectivamente.

$\mathrm{Na}$ Figura 3, pode-se observar a variação média do teor de água no solo até $0,50 \mathrm{~m}$ de pro- fundidade. Houve pequena variação até os 30 DAS em decorrência dos tratamentos ainda não terem sido iniciados. A partir desta data, com a aplicação das cinco diferentes lâminas, pode-se visualizar nítida diferença na umidade do solo entre os tratamentos.

Esses valores indicam que houve um gradiente decrescente do teor de água no solo, onde o tratamento de maior lâmina permaneceu, na maioria dos dias, próximo à capacidade de campo $(22 \%)$ e o de menor lâmina próximo ao ponto de murcha permanente (9\%). Quanto aos tratamentos intermediários (100\% e $75 \%$ da ETo), o teor de água no solo permaneceu próximo aos limites de água disponível para cultura do

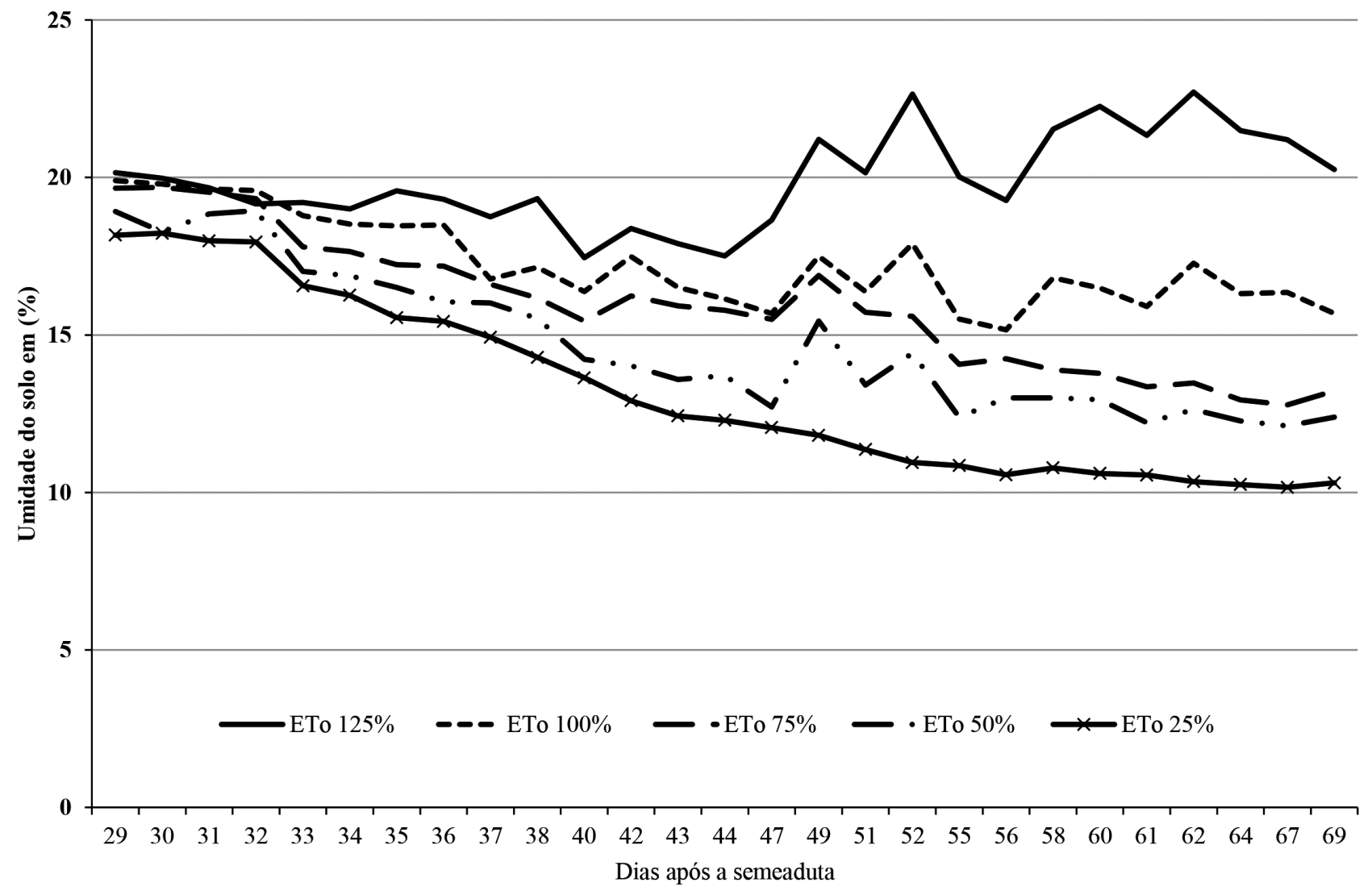

FIGURA 3. Variação da umidade média do solo até a profundidade de $0,50 \mathrm{~m}$, ao longo do ciclo fenológico do milho verde em função das lâminas de irrigação aplicadas (percentual da evapotranspiração de referência - \% ETo). Embrapa Meio-Norte, Teresina-PI, 2009. 
milho que, segundo Doorembos \& Kassam (1994), é de $50 \%$.

A água disponível ao aplicar as maiores lâminas ( $125 \%$ da ETo e $100 \%$ da ETo) mantiveramse acima de $80 \%$ em todo o perfil do solo $(0,00 \mathrm{~m}$ a $0,50 \mathrm{~m}$ ) (Figura 4). Já as lâminas de $75 \%$ da ETo e $50 \%$ da ETo apresentaram comportamentos semelhantes entre si em quase todo o perfil, estabelecendo-se entre $60 \%$ e $80 \%$ da disponibilidade de água. Quanto à aplicação da menor lâmina de irrigação ( $25 \%$ da ETo), observou-se uma disponibilidade de água com valores entre $40 \%$ e $49 \%$ em todo o perfil, constatando-se um maior déficit hídrico.
Fornasieri Filho (2007) relata que, quando ocorre déficit hídrico até $0,30 \mathrm{~m}$ de profundidade, a planta de milho fica ainda mais vulnerável, uma vez que a maior parte das raízes se encontra nesta profundidade.

A análise de regressão do índice de área foliar (Tabela 3) aos 44 DAS apresentou resposta linear $(\mathrm{p}<0,01)$ e também quadrática $(\mathrm{p}<0,05)$. $\mathrm{E}$ aos 58 DAS apresentou-se linear $(\mathrm{p}<0,01)$ e quadrática $(\mathrm{p}<0,01)$ à lâmina de irrigação, uma vez que a diferenciação dos tratamentos teve inicio apenas aos $30 \mathrm{DAS}$, época da primeira medição do IAF.

Capacidade de água disponível (\%)

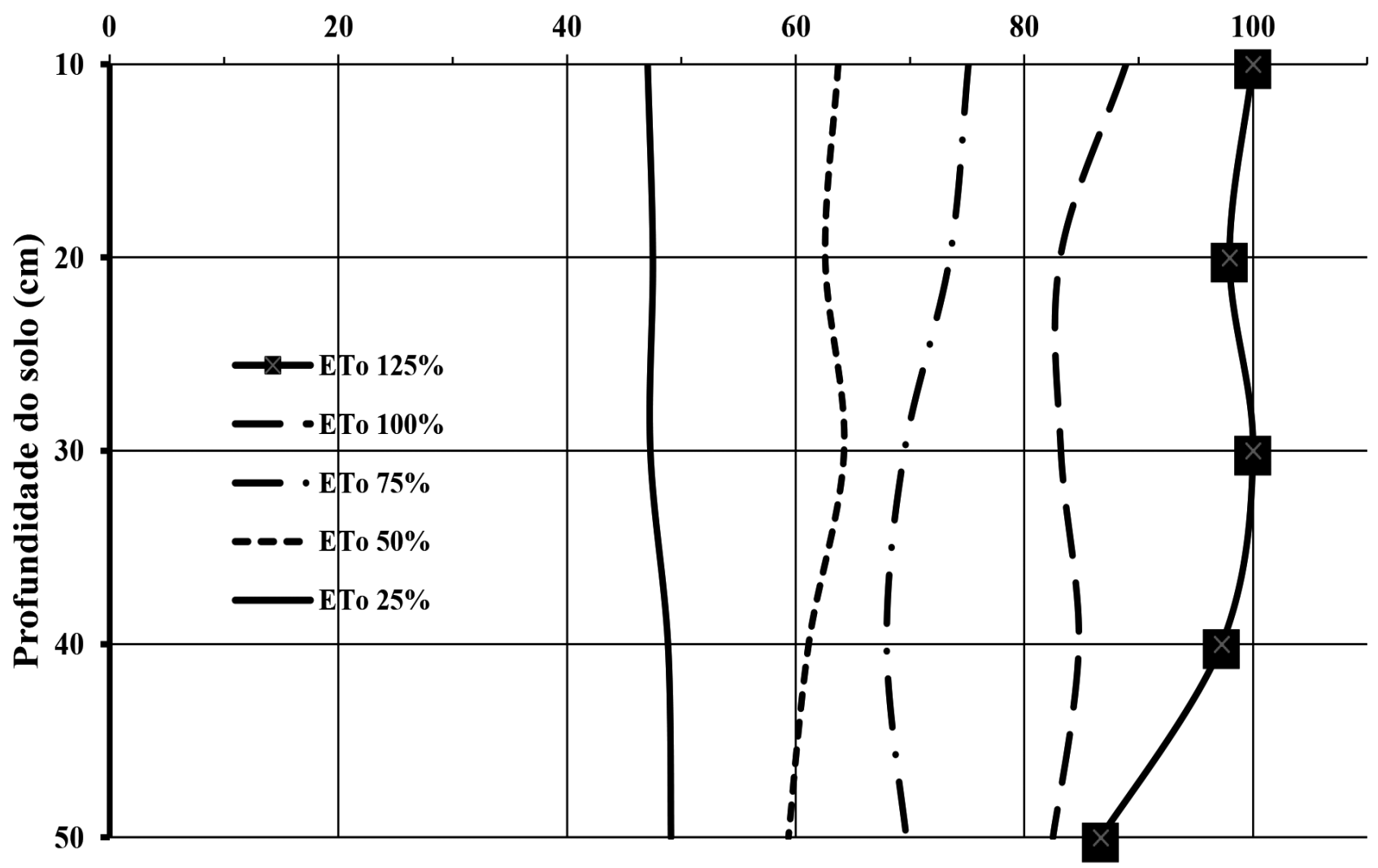

FIGURA 4. Capacidade de água disponível para o milho verde após a diferenciação das lâminas de irrigação. 
Nesse período de 30 DAS, os IAFs apresen- meira época, com valores médios variando de 3,05 taram pequena variação entre as cinco lâminas, com valores entre 1,31 e 2,0 (Figura 5). A partir daí, os IAFs cresceram e, aos 44 dias após a semeadura, apresentaram valores maiores que na pri-

a 3,86. A diferença dos IAFs entre os tratamentos com maiores e menores lâminas aumentou aos 58 DAS, com valores médios variando de 1,94 (ETo $25 \%$ ) a 3,70 (ETo $125 \%)$.

TABELA 3. Resumo do uso da regressão na análise de variância correspondente ao IAF do híbrido duplo de milho AG1051, dentro das lâminas nas épocas aos 44 e aos 58 dias após a semeadura (DAS). Teresina-PI, 2009. Veja se é possível colocar (estender) as linhas horizontais até as margens da folha.

\begin{tabular}{cccc}
\hline \multirow{2}{*}{ FV } & G.L & \multicolumn{2}{c}{ Quadrado Médio } \\
\cline { 3 - 4 } L’d. DAS & 1 & $1,458795^{* *}$ & DAS 58 \\
L“ d. DAS & 1 & $0,554937^{*}$ & $0,799378^{* *}$ \\
Desv.Reg & 2 & $0,0111943^{\text {ns }}$ & $0,207899^{\text {ns }}$ \\
BL & 3 & 0,251913 & 0,251913 \\
Resíduo & 42 & 0,112145 & 0,112145 \\
\hline
\end{tabular}

$$
\mathrm{CV}(\%) 12,11
$$

$\mathrm{ns}, * * * *$ = não significativo e significativo a $1 \%$ e a $5 \%$ de probabilidade,respectivamente, pelo Teste $\mathrm{F}$.

$\diamond$ ETo $125 \% \quad \square$ ETo $100 \% \quad \Delta$ ETo $75 \% \quad \times$ ETo $50 \% \quad+$ ETo $25 \%$

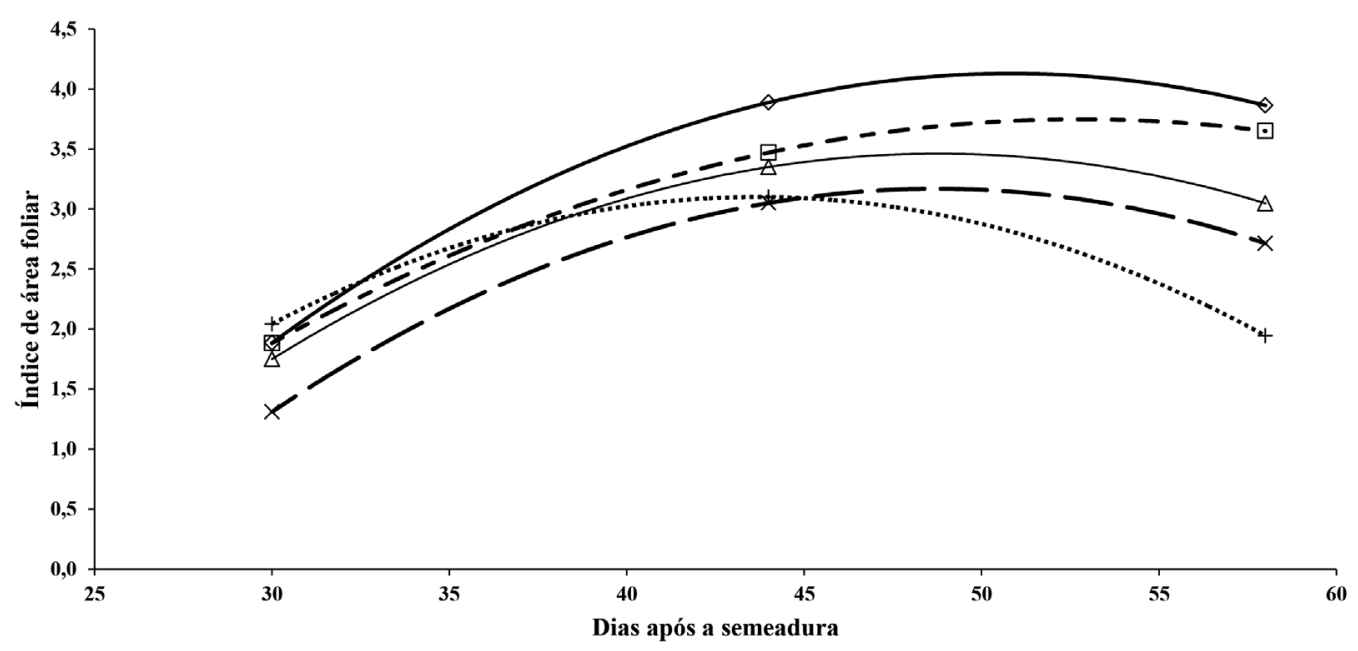

FIGURA 5. Índice de área foliar do híbrido duplo de milho AG1051, em função das lâminas de irrigação aplicadas, Teresina-PI, 2009. 
Somente próximo ao estádio R3, correspondente a grão pastoso quando pode ser comercializado como milho verde, é que se percebe um declínio mais proeminente nos tratamentos de $75 \%$ da ETo, $50 \%$ da ETo e $25 \%$ da ETo. Esses resultados são justificados em decorrência do déficit hídrico mais intenso.

Uma das respostas mais proeminentes das plantas ao déficit hídrico consiste no decréscimo da área foliar, fechamento dos estômatos, aceleração na senescência e abscisão das folhas (Taiz \& Zeiger,1991), contribuindo para a redução da produtividade da planta. Esses efeitos puderam ser observados nesta pesquisa, notadamente nos tratamentos cujas lâminas de irrigação corresponderam a $25 \%$ e a $50 \%$ da ETo, em que foram encontrados os menores valores do IAF e as mais baixas produtividades de espigas, conforme relatado anteriormente.

Parizi (2007), em pesquisa realizada no município de Santiago-RS, observou o aumento do IAF da cultura do milho cultivar AGN 2012 até aproximadamente os 74 dias após a emergência (estádio R1), quando atingiu o maior crescimento de IAF com a maior média $(6,08)$ para o tratamento de $80 \%$ da ETo. Após esta fase, já aos 90 dias após a emergência, ocorreu um declínio devido à senescência e à queda de folhas, coincidindo com o estádio de grão pastoso. Este mesmo autor relata que os dados do IAF da cultura do milho ajustaram-se a uma equação de segundo grau, com coeficiente de determinação $\left(\mathrm{R}^{2}=0,96\right)$, corroborando com este trabalho.

Condição de redução do IAF, em Sete Lagoas-MG, foi observada por Andrade et al. (2008), em decorrência do déficit hídrico, semelhante ao encontrado neste trabalho. Os autores encontraram IAFs com média de 2,18 no estágio V8, 2,6 no estágio R1 e 1,85 no estágio R6 que, segundo Ritchie et al. (2003), se enquadram no estádio vegetativo (oitava folha), no estádio reprodutivo (florescimento) e na maturação fisiológica, respectivamente.

Com relação ao teor de clorofila (Tabela 4), observa-se que houve significância $(\mathrm{p}<0,01)$ de lâmina em função das épocas de amostragem aos $38,45,52$ e 59 DAS para o teor de clorofila total (TCT).

TABELA 4. Resumo do uso da regressão na análise de variância correspondente ao teor de clorofila total do híbrido duplo de milho AG1051, dentro das lâminas nas épocas 38, 45, 52 e 59 dias após a semeadura (DAS). Teresina-PI, 2009.

\begin{tabular}{cccccc}
\hline \multirow{2}{*}{ FV } & G.L & \multicolumn{4}{c}{ Quadrado Médio } \\
\cline { 3 - 5 } & & DAS 38 & DAS 45 & DAS 52 & DAS 59 \\
\hline L' d. DAS & 1 & $270,358^{* *}$ & $257,312^{* *}$ & $501,565^{* *}$ & $1037,31^{* *}$ \\
Desv.Reg & 3 & $20,7668^{\text {ns }}$ & $0,7039^{\text {ns }}$ & $4,9697^{\text {ns }}$ & $13,0515^{\text {ns }}$ \\
BL & 3 & 18,5806 & 18,5806 & 18,5806 & 18,5806 \\
Resíduo & 57 & 32,9695 & 32,9695 & 32,9695 & 32,9695 \\
\hline CV(\%) 9,8 & & & & \\
\hline
\end{tabular}

ns, $* * * *$ não significativo e significativo a $1 \%$ e a $5 \%$ de probabilidade pelo Teste $\mathrm{F}$. 
O efeito das lâminas ajustou-se a uma função linear, apresentando incremento dos valores analisados considerando o tratamento de $125 \%$ da ETo, com 340,57 $\mathrm{mm}$ aplicados, em relação ao tratamento de $25 \%$ da ETo, com $165,51 \mathrm{~mm}$, proporcionando o menor teor de clorofila total. Na primeira época (38 DAS), ocorreu redução de $15,2 \%$, com valores de 64,6 no teor de clorofila na folha para a lâmina de $125 \%$ da ETo e de 54,7 para a menor lâmina aplicada de $25 \%$ da ETo. Esta variação pode ser atribuída aos oito dias entre a diferenciação das lâminas e a primeira leitura feita com o clorofiLOG.

Uma redução em torno de $15 \%$ também foi observada aos 45 DAS, quando foi feita a segunda leitura, com valores de 65,2 e 55,4 no teor de clorofila na folha para a maior ( $125 \%$ da ETo) e menor lâminas (25\% da ETo), respectivamente. À medida que aumentou o período de déficit hídri- co, maiores foram as diferenças do teor total de clorofila entre os tratamentos (Figura 6).

Aos 52 e aos 59 DAS, os teores de clorofila total do tratamento de menor lâmina foram de 19,4\% e $28,9 \%$; portanto, menores que o tratamento $125 \%$. Isso demonstra efeito deletério do déficit hídrico sobre a clorofila, que também foi observado por Viana et al. (2004) e por Bastos et al. (2011), avaliando o déficit hídrico sobre a produção de milho e de feijão caupi, respectivamente.

Quanto ao valor referente à menor lâmina, este foi semelhante ao resultado encontrado por Viana et al. (2004) que, avaliando o efeito do estresse hídrico sobre o teor relativo de clorofila de linhagens de milho, obtiveram 42,0 de teor de clorofila total para linhagem sensível.

A produtividade de espigas verdes empalhadas e despalhadas respondeu de forma linear crescente às lâminas de irrigação, alcançando

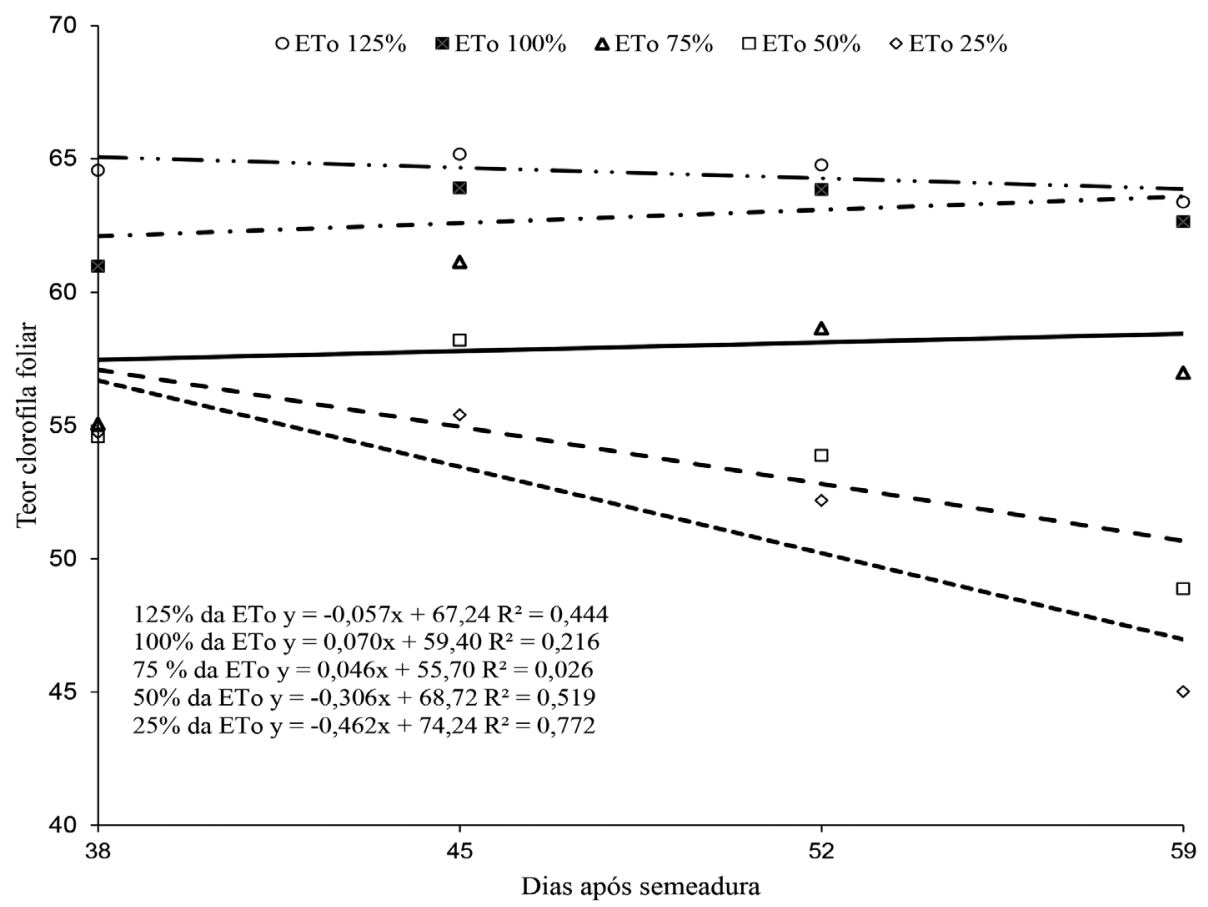

FIGURA 6. Teor de clorofila na folha (TCT) em função da época de amostragem para as lâminas de irrigação aplicadas, Teresina-PI, 2009. 
$13.453,13 \mathrm{~kg} \mathrm{ha}^{-1}$ e $8.465,62 \mathrm{~kg} \mathrm{ha}^{-1}$ (Figura 7), para o tratamento $125 \%$ da ETo $(340,57 \mathrm{~mm})$, respectivamente.

Na menor lâmina aplicada $165,51 \mathrm{~mm}(25 \%$ da ETo), estas produtividades foram de 1.420,63 $\mathrm{kg} \mathrm{ha}^{-1}$ e 1.007,92 $\mathrm{kg} \mathrm{ha}^{-1}$, respectivamente. O coeficiente de regressão indica que, para cada milímetro de água aplicada, ocorre um incremento na produção de espiga verde empalhada de $70,31 \mathrm{~kg} \mathrm{ha}^{-1} \mathrm{e}$ $45,19 \mathrm{~kg} \mathrm{ha}^{-1}$ para a despalhada. Este incremento pode ser resultado do maior nível de conteúdo de água no solo, que proporciona maior desenvolvimento foliar, consequentemente maior produção de fotoassimilados e, portanto, maior produtividade de espigas verdes da lâmina com $125 \%$ da ETo em relação à aplicação de $25 \%$ da ETo.
Resposta linear também foi observada por Biscaro et al. (2008) para produtividade de espigas verdes, quando trabalharam com 25\%, 50\%, 100\% e $200 \%$ do tempo de irrigação com base na metodologia de Bernardo et al. (2005) para manejo de irrigação localizada.

A redução de produtividade de espiga verde foi influenciada pelo baixo teor de umidade no solo, o que também deve ter causado os menores valores de índice de área foliar e teor de clorofila total. Segundo Kasele et al. (1994), o milho é relativamente tolerante ao déficit hídrico durante a fase vegetativa, porém demonstra extrema sensibilidade nas fases de florescimento e de enchimento dos grãos, o que pode acarretar decréscimo no rendimento. Também sob condições de déficit hí-

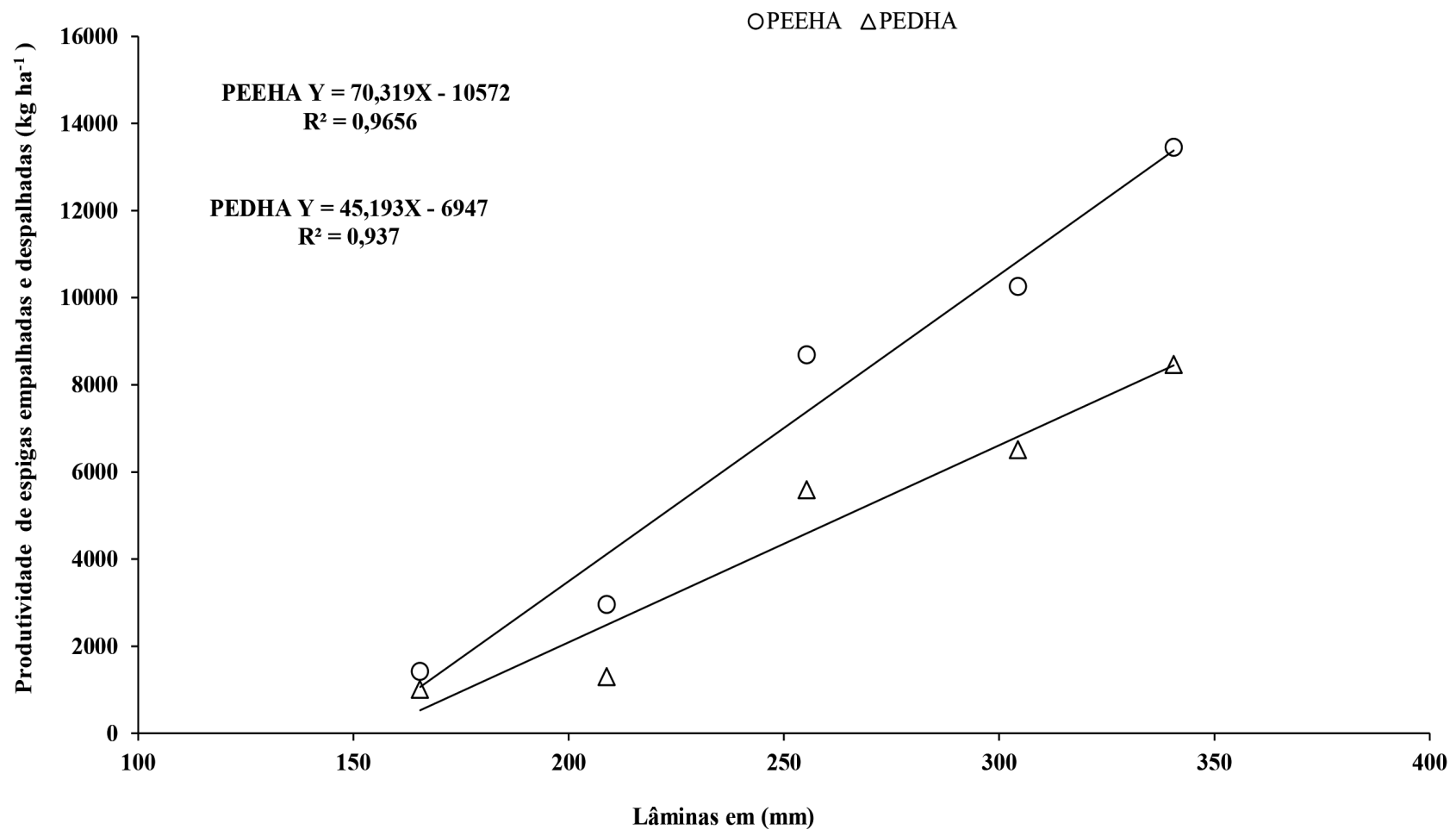

FIGURA 7. Produtividade de espiga empalhada e despalhada por hectare em função das lâminas de irrigação aplicadas. Teresina-PI, 2009. 
drico, o grau de redução da produtividade do milho depende da intensidade do estresse, da sua duração e do estádio em que ele ocorre (Serpa et al. 2012).

Pode-se perceber uma correlação positiva significativa $(\mathrm{p}<0,01)$ da produtividade de espigas verdes despalhadas com o índice de área foliar e o teor de clorofila total (Tabela 5), uma vez que o aumento ou a redução de um desses parâmetros proporciona também aumento ou redução da produtividade de espigas.

Resultados encontrados por Almeida et al. (2003) mostraram uma associação positiva e significativa entre o IAF e o rendimento de grãos. Também
Mota et al. (2012), para o caractere produtividade de grão, mostram que esse teve uma correlação positiva e significativa $(\mathrm{p}<0,05)$ com vários parâmetros fisiológicos, como taxa de fotossíntese, transpiração foliar, condutância estomática e teor de clorofila.

A eficiência do uso da água(EUA) é também um importante parâmetro para se conhecer a capacidade de uma espécie em adaptar-se a determinado ambiente, assim como avaliar a produtividade das plantas.

Os maiores valores $2,48 \mathrm{~kg} \mathrm{~m}^{-3}, 1,84 \mathrm{~kg} \mathrm{~m}^{-3} \mathrm{e} 2,09$ $\mathrm{kg} \mathrm{m}^{-3}$ foram obtidos para os tratamentos com maior volume de água aplicada, os quais apresentaram as maiores produtividades de espigas verdes (Figura 8).

TABELA 5. Estimativas de correlação entre a produtividade de espiga despalhada (PEED), o índice de área foliar (IAF) e o teor de clorofila total (TCT) da cultivar de milho verde AG1051.

\begin{tabular}{cccc}
\hline Parâmetro & PEED & IAF & TCT \\
\hline PEED & 1 & & \\
IAF & $0,80^{* *}$ & 1 & \\
TCT & $0,93^{* *}$ & $0,83^{* *}$ & 1 \\
\hline
\end{tabular}

** Significativo ao nível de $1 \%$ de probabilidade, pelo teste $\mathrm{F}$.

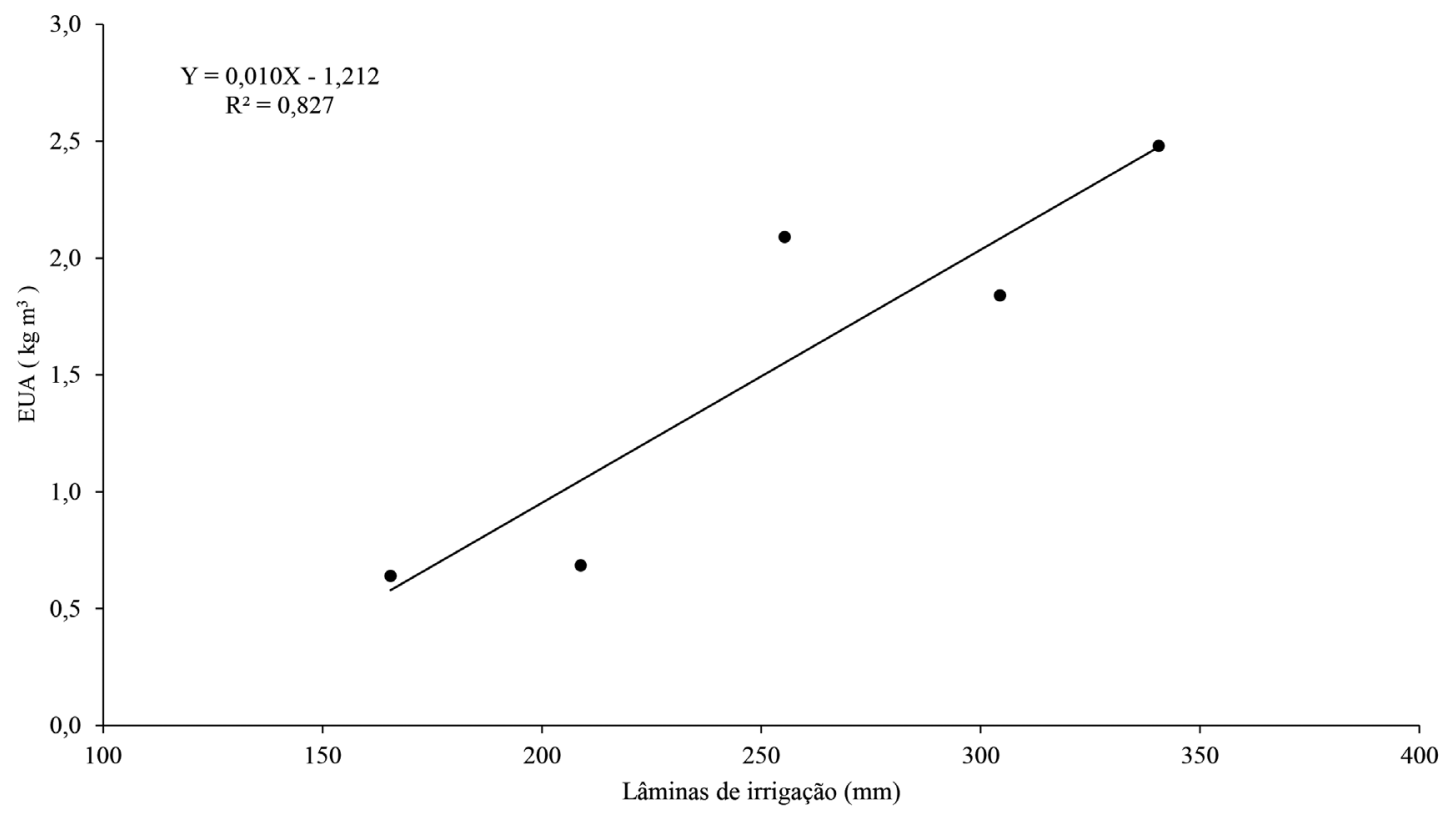

FIGURA 8. Eficiência do uso da água do híbrido comercial AG1051 em função das lâminas de irrigação aplicadas, Teresina-PI, 2009. 
Os menores valores de EUA $\left(0,68 \mathrm{~kg} \mathrm{~m}^{-3} \mathrm{e}\right.$ $0,64 \mathrm{~kg} \mathrm{~m}^{-3}$ ) resultaram da aplicação das lâminas de $50 \%$ e $25 \%$ da ETo, respectivamente. O coeficiente de regressão revela que, para cada milímetro de lâmina de irrigação aplicado, ocorre um incremento de $0,01 \mathrm{~kg}$ de espigas verdes. Este comportamento induz a afirmar que a cultura ainda poderia proporcionar maiores valores de produção com aumento da lâmina aplicada.

Resultados encontrados por Souza et al. (2011) para produtividade de milho grão apresentaram comportamento linear para EUA, com valores de $0,46 \mathrm{~kg}$ $\mathrm{m}^{-3}, 0,58 \mathrm{~kg} \mathrm{~m}^{-3}, 0,67 \mathrm{~kg} \mathrm{~m}^{-3}, 0,72 \mathrm{~kg} \mathrm{~m}^{-3}$ e $0,77 \mathrm{~kg}$ $\mathrm{m}^{-3}$ para $0 \%, 50 \%, 75 \%, 100 \%$ e $125 \%$ da ETo, respectivamente.

Esses valores apresentam-se menores que os resultados obtidos para os tratamentos $75 \%, 100 \%$ e $125 \%$ da ETo usados nesta pesquisa.

Parizi (2007), que trabalhou com quatro estratégias de irrigação (EI): $120 \%$; 100\%; 80\%; e 60\% da ETo na cultura do milho grão, verificou tendência linear da EUA entre os tratamentos, com valor de 3,07 $\mathrm{kg} \mathrm{m}^{-3}$ para menor estratégia e de $3,46 \mathrm{~kg}$ $\mathrm{m}^{-3}$ para $100 \%$ da ETo, esse configurando a maior média.

\section{Conclusões}

O aumento da lâmina de irrigação favorece uma resposta linear crescente da produtividade de espiga verde empalhada e despalhada.

O déficit hídrico a partir do estádio V6 (sexta folha completa) reduz linearmente o índice de área foliar e o teor de clorofila.

Os parâmetros fisiológicos índice de área foliar e teor de clorofila se correlacionam positivamente com a produtividade de espigas despalhadas.
A mais alta eficiência do uso da água $(2,48$ $\mathrm{Kg} \mathrm{m}^{-3}$ ) foi obtida com aplicação da maior lâmina $(340,57 \mathrm{~mm})$.

\section{Agradecimentos}

Ao programa de pós-graduação em Agronomia e Produção Vegetal da Universidade Federal do Piauí (UFPI), pela oportunidade de aprendizagem e pesquisa. À Embrapa Meio-Norte, por todo apoio estrutural na implantação do experimento. Ao meu orientador e também coorientador, por todos os ensinamentos repassados.

\section{Referências}

ALBUQUERQUE, P. E. P de; RESENDE, M. Irrigação: manejo de irrigação. In: CRUZ, J. C. (Ed.). Cultivo do milho. 5. ed. Sete Lagoas: Embrapa Milho e Sorgo, 2009. (Embrapa Milho e Sorgo. Sistemas de produção, 1).

ALLEN, R. G.; PEREIRA, L. S.; RAES, D.; SMITH, M. Crop evapotranspiration: guidelines for computing crop water requirements. Rome: FAO, 1998. 300 p. (FAO. Irrigation and Drainage Paper, 56).

ALMEIDA, de M. L.; SANGOI, L.; NAVA, I. C.; GALIO, J.; TRENTIN, P.S.; RAMPAZZO, C. Crescimento inicial de milho e sua relação com o rendimento de grãos. Ciência Rural, Santa Maria, v. 33, n. 2, p. 325-332, mar-abr, 2003.

ANDRADE, C. L. T.; AMARAL, T. A.; GOMIDE, R. L.; ALBUQUERQUE, P. E. P.; HEINEMANN, A. B.; MENDES, A. P.; ALVES, F. F.; ARAUJO, S. G. Área Foliar e Produtividade de Grãos de Cultivares de Milho, Submetidas à Déficit Hídrico,em Sete Lagoas, MG. In: CONGRES- 
SO NACIONAL DE MILHO E SORGO, 27., SIMPÓSIO BRASILEIRO SOBRE A LAGAR-

TA-DO-CARTUCHO, SPODOPTERA FRUGIPERDA, 3; WORKSHOP SOBRE MANEJO E ETIOLOGIA DA MANCHA BRANCA DO MILHO, 2008. Londrina. Agroenergia, Produção de Alimentos e Mudanças Climáticas: Desafios para Milho e Sorgo: palestras e trabalhos apresentados. Londrina: IAPAR, 2008. 1 CD-ROM.

BASTOS, E. A.; ANDRADE JÚNIOR, A. S. Boletim Agro meteorológico do ano de 2007 para o município de Teresina, PI. Teresina: Embrapa Meio-Norte, 2008. 37 p. (Embrapa Meio-Norte. Documentos, 181).

BASTOS, E. A.; NASCIMENTO, S. P do; SILVA, E. M da; FREIRE FILHO, F. R.; GOMIDE, R. L. Identificação de genótipos de feijão-caupi tolerantes à seca. Revista Ciência Agronômica, Fortaleza, v. 42, n. 1, p. 100-107, jan-mar, 2011. BERNARDO, S.; SOARES, A. A.; MANTOVANI,

E. C. Manual de irrigação. 7.ed.Viçosa: UFV, 2005. $611 \mathrm{p}$.

BISCARO, G. A.; MAIA, S. C. M.; SILVA, T. R. B. da. Influencia da aplicação de água no milho verde irrigado na região do cerrado Sul-MatoGrossense. Agrarian, Dourados, v. 1, n. 1, p. 67-77, jul./set. 2008.

DOORENBOS, J.; KASSAM, A. M. Efeito da água no rendimento das culturas. Campina Grande: UFPB, 1994. 306 p. (FAO. Estudos FAO. Irrigação e Drenagem, 33)

FORNASIERI FILHO, D. Manual da cultura do milho. Jaboticabal: Funep, 2007. 276 p.

GORDON, W. B.; RANEY, R. J.; STONE, L. R. Irrigation management practices for corn production in north central Kansas. Journal of Soil and Water Conservation, Ankeny, v. 50, n. 4, p. 395-398, 1995.

KASELE, I. N.; NYIRENDA, F.; SHANAHAN, F. J.; NIELSEN, D. C.; D'ANDRIA, R. Ethephon alters corn growth, water use, and grain yield under drought stress. Agronomy Journal, Madison, v. 86, p. 283-288, 1994.

MADDONNI, G. A.; OTEGUI, M. E. Leaf area, light interception, and crop development in maize. Fild Crops Research, Amsterdam, v. 48, p. 8187, 1996.

MOTA, L. H. de S.; HEINZ, R.; GARBIATE, M. V.; NETO, L. V. N.; CORREIAS, A. M. P.; TAKESHITA, R. F. P. Correlação Entre a Produtividade e Parâmetros Fisiológicos de Cultivares de Milho Sob Diferentes Espaçamentos. In: CONGRESSO NACIONAL DE MILHO E SORGO, 29. 2012, Águas de Lindóia. Diversidade e inovações na era dos transgênicos: resumos expandidos. Campinas: Instituto Agronômico; Sete Lagoas: Associação Brasileira de Milho e Sorgo, 2012. CD-ROM

PARIZI, A. R. C. Efeito de diferentes estratégias de irrigação sob as culturas de feijão Phaseolus vulgaris $\mathrm{L}$. ) e milho (Zea mays $\mathrm{L}$.) na região de Santiago, RS. 2007. 124 f. Dissertação (Mestrado em Engenharia Agrícola)- Universidade Federal de Santa Maria, Santa Maria.

PETRY, M. T.; ZIMMERMANN, F. L.; CARLESSO, R.; MICHELON, C. J.; KUNZ, J. H. Disponibilidade de água do solo ao milho cultivado sob sistemas de semeadura direta e preparo convencional. Revista Brasileira de Ciência do Solo, Campinas, v. 31, n. 3, p. 531-539, 2007.

RITCHIE, S. W.; HANWAY, J. J.; BENSON, G. O. Como a planta de milho se desenvolve. Pira- 
cicaba: Potafos, 2003. p.1-20. (Potafos. Arquivo Agronômico, 15)

SAS INSTITUTE INC. SAS/STAT user'sguide. Version 8.1. Cary, 2002. v. 1, 890 p.

SANTOS, H. G. dos; JACOMINE, P. K. T.; ANJOS, L. H. C. dos; OLIVEIRA, V. A. de; OLIVEIRA, J. B. de; COELHO, M. R.; LUMBRERAS, J. F.; CUNHA, T. J. F. (Ed.). Sistema brasileiro de classificação de solos. 2. ed. Rio de Janeiro: Embrapa Solos, 2006. 306 p.

SANTOS, O. O.; FALCÃO, H.; ANTONINO, A. C. D.; LIMA, J. R. S.; LUSTOSA, B. M.; SANTOS, M. G. Desempenho ecofisiológico de milho, sorgo e braquiária sob déficit hídrico e reidratação. Bragantia, Campinas, v. 73, n. 2, p. 203-212, 2014.

SERPA, M. da S.; SILVA, P. R. F da; SANGOI, L.; VIEIRA, V. M. V.; MARCHESI, D. R. Densidade de plantas em híbridos de milho semeados no final do inverno em ambientes irrigados e de sequeiro. Pesquisa Agropecuaria Brasileira, Brasília, DF, v. 47, n. 4, p. 541-549, abr. 2012.

SOUZA, L. S. B de; MOURA, M. S. B de; SEDIYAMA, G. C.; SILVA, T. G. F da. Eficiência do uso da água das culturas do milho e feijão-caupi sob sistemas de plantio exclusivo e consorciado no semiárido brasileiro. Bragantia, Campinas, v. 70, n. 3, p. 715-721, 2011.

TAIZ, L.; ZEIGER, E. Plant Physiology. California: California: The Benjamin: Cummings, 1991. 559 p.
THORNTHWAITE, C. W.; MATHER, J. R. The water balance. Centerton: Drexel Institute of Technology - Laboratory of Climatology, 1955. 104 p. (Publication in Climatology, vol. VIII, n.1).

TORRES NETTO, A.; CAMPOSTRINI, E.; OLIVEIRA, J. G.; SMITH, R. E. B. Photosynthetic pigments, nitrogen, chlorophyll a fluorescence and SPAD-502 readings in coffee leaves. Scientia Horticulturae, Amsterdam, v.104, p.199209, 2005.

VIANA, M. C. M.; DURÃES, F. O. M.; QUEIROZ, C.G.S.; SOUZA, I.R.P.; ALBUQUERQUE, P. E. P. Produção de Fitomassa e Teor de Clorofila em Linhagens de Milho Submetidas ao Défice Hídrico. In: CONGRESSO NACIONAL DE MILHO E SORGO, 25. SIMPÓSIO BRASILEIRO SOBRE A LAGARTA-DO-CARTUCHO, SPODOPTERA FRUGIPERDA, 1. 2004, Cuiába. Da agricultura familiar ao agronegócio: tecnologia, competitividade e sustentabilidade - [resumos expandidos] Sete Lagoas: Abms, Embrapa Milho e Sorgo; Cuiába: Empaer-MT, 2004. 1 CD ROM

WATSON, D. J. Comparative physiological studies on the growth of field crops.I variation in net assimilation rate and leaf area between species and varieties, and within between years. Annals of Botany, London, v. 11, n. 42, p. 41-76, 1947. 